\title{
Pengaruh Budaya Kerja Pengemudi Angkutan Umum Kota Terhadap Kepuasan Penumpang di Kota Padang
}

\author{
Influence of work culture of the city transport driver to the passenger satisfaction in \\ Padang City
}

\author{
Digna Kasandra, Aldri Frinaldi, Dasman Lanin \\ Jurusan Ilmu Administrasi Publik \\ Fakultas Ilmu Sosial, Universitas Negeri Padang \\ Email : dignakasandra281@gmail.com
}

\begin{abstract}
Abstrak
Keluhan yang lazim diungkapkan oleh masyarakat pengguna layanan angkutan kota berkaitan dengan budaya kerja pengemudi angkutan kota antara lain pengemudi angkutan kota yang mengambil dan menurunkan penumpang di luar pangkalan dan suka ngetem, memutar musik dengan volume tinggi, ugal-ugalan dan mengemudikan angkutan kota dengan kecepatan tinggi dan kebut-kebutan di jalan raya dan rem mendadak jika melihat ada calon penumpang di pinggir jalan. Penelitian ini bertujuan untuk menganalisis pengaruh budaya kerja pengemudi angkutan kota terhadap kepuasan penumpang di Kota Padang. Penelitian ini menggunakan metode kuantitatif deskriptif. Sampel dalam penelitian ini adalah 400 penumpang angkutan kota di Kota Padang. Pengambilan sampel menggunakan rumus slovin dan teknik Simple Random Sampling. Pengumpulan data dilakukan dengan menggunakan angket dengan pengukuran skala likert dan wawancara. Data dianalisis menggunakan teknik analisis uji regresi linier sederhana. Hasil penelitian menunjukkan bahwa terbukti adanya pengaruh yang signifikan budaya kerja pengemudi angkutan kota terhadap kepuasan penumpang di Kota Padang sebesar 19,1\%. Berdasarkan hasil ini perlu upaya pemerintah kota Padang merumuskan suatu bimbingan teknis kepada para pengemudi angkutan kota tentang nilai-nilai budaya kerja yang dapat meningkatkan kepuasan penumpang.
\end{abstract}

Keywords: Budaya Kerja; Kepuasan Penumpang ; Angkutan Kota

\begin{abstract}
Complaints that are commonly expressed by the community of users of urban transport services associated with the working culture of the city's transport drivers include city transport drivers who take and drop off passengers outside the base and like to stop waiting passengers, play music with high volume, reckless and drive city transportation at high speed on the highway and brake suddenly if they see a prospective passenger on the roadside. The purpose of this research is to analyze the influence of work culture of city transport driver to passenger satisfaction in Padang City. The method used in this research is quantitative method with descriptive approach. The sample in this research were 400 passenger of city transportation in Padang City. Sampling using slovin formula and Simple Random Sampling
\end{abstract}


technique. Data collected by using questionnaires with likert scale measurements and interviews and also Data were analyzed using simple linear regression analysis technique. The results of this study indicate that there is a significant effect of the work culture of the city transport driver to the satisfaction of passengers in the city of Padang by $19.1 \%$. Based on these results it is necessary that the Padang city government efforts to formulate technical guidance to the drivers of urban transport on the values of work culture that can improve passenger satisfaction

\section{Keywords: Work Culture; Passengers Satisfaction ; Urban Transportation}

\section{A. Pendahuluan}

Sektor transportasi dewasa ini memegang peranan penting untuk menunjang kegiatan perekonomian dan pembangunan suatu Negara serta untuk membantu masyarakat memenuhi kebutuhan hidup dalam kegiatan sehari-hari. Zulfiar Sani (2013:1) menyatakan bahwa transportasi merupakan sebuah proses pemindahan manusia atau barang dari satu tempat ke tempat lainnya dengan menggunakan sebuah angkutan yang digerakkan oleh manusia atau mesin. Setiap masyarakat yang melakukan perpindahan untuk memenuhi kebutuhan hidup maka akan bergerak dari satu tempat ke tempat lain seperti dari rumah ke tempat tujuan, misalnya ke pasar, tempat bekerja, rumah sakit, sekolah atau ke tempat lain yaitu ke tempat rekreasi maupun untuk melaksanakan kegiatan sosial. Untuk itu diperlukan alat penunjang transportasi untuk melaksanakan berbagai kegiatan. Salah satu alat transportasi yang menjadi alternatif bagi masyarakat yang tidak memiliki kendaraan pribadi agar cepat sampai di tempat tujuan adalah angkutan umum.

Angkutan umum merupakan salah satu urat nadi penyokong kehidupan masyarakat di kawasan perkotaan, termasuk di Kota Padang, Provinsi
Sumatera Barat. Salah satu bentuk angkutan umum ini adalah kendaraan angkutan dalam kota yang melayani rute/trayek tertentu berdasarkan perizinan dari instansi yang berwenang. Angkutan umum tersebut disebut juga dengan istilah Angkutan Kota (Angkot). Angkutan Kota (Angkot) di Kota Padang berdasarkan peraturan daerah Kota Padang nomor 11 tahun 2005 tentang ketertiban umum dan ketentraman masyarakat adalah angkutan dari suatu tempat ke tempat lain dalam kota Padang dengan menggunakan mobil bus umum atau mobil penumpang umum yang terikat dalam trayek.

Angkot di Kota Padang Berjumlah 2145 armada dalam 72 trayek. Angkot Padang memiliki bagian luar badan mobil dihiasi dengan berbagai macam stikter yang menutupi sebagian badan mobil, bumper mobil dibuat rendah hampir menyentuh aspal jalan, sedangkan pada bagian dalam dihiasi dengan lampu klap-klip warnawarni, televisi dan pemasangan sound system di dalam angkot. Sering kali upaya pengemudi angkot mengejar target setoran, maka dalam mengemudikan angkot dirasakan oleh masyarakat pengguna layanan pada ketidaknyamanan. Keluhan yang lazim diungkapkan oleh masyarakat pengguna layanan angkutan kota berkaitan 
dengan budaya kerja pengemudi angkot Kota Padang antara lain dalam bentuk sikap pengemudi angkot yang mengambil dan menurunkan penumpang di luar pangkalan dan pengemudi angkot yang suka ngetem (sedang berhenti menunggu penumpang) di berbagai tempat di luar pangkalan untuk mendapatkan penumpang yang lebih banyak dengan waktu yang cukup lama seperti di Pasar Raya dan sikap pengemudi angkot yang memutar musik dengan volume tinggi membuat penumpang menjadi tidak nyaman berada di dalam angkot (Sumber: Koran Online Padang Ekpress 2015).Selanjutnya budaya kerja (dalam bentuk suatu perilaku) pengemudi angkot yang ugal-ugalan dan mengemudikan angkot dengan kecepatan tinggi dan kebut-kebutan di jalan raya serta saling mendahului dan rem mendadak, jika melihat ada calon penumpang di pinggir jalan sehingga membuat penumpang cemas dan tidak nyaman (Sumber: Koran Online Padang Ekpress 2015). Berdasarkan permasalahan tersebut peneliti tertarik untuk menganalisis pengaruh budaya kerja pengemudi angkutan kota terhadap kepuasan penumpang di Kota Padang.

\section{B. Tinjauan Pustaka}

\section{a. Budaya Kerja}

Aldri Frinaldi, (2011; 2012; 2014; 2017a), mengungkapkan bahwa "Work culture is aphilosophy that is based on a view of life as values into the nature, habits and driving forces, entrenched in a community group or organization, which is reflected in the attitude then becomes behaviors, beliefs, ideals, views, and actions" (Budaya kerja adalah filsafat yang didasarkan pada pandangan hidup sebagai nilai ke dalam sifat, kebiasaan dan kekuatan pendorong, tertanam dalam kelompok masyarakat atau organisasi, yang tercermin dalam sikap kemudian menjadi perilaku, kepercayaan, cita-cita, pandangan, dan tindakan).

Menurut Asyrori (2014:1722) budaya kerja merupakan sebagai sikap dan perilaku individu dan kelompok yang didasari atas nilai-nilai yang diyakini kebenarannya dan telah menjadi sifat serta kebiasaan dalam melaksakan tugas dan pekerjaan seharihari. Budaya kerja menurut Budi Paramita dalam Taliziduhu Ndraha (2005:208) mengemukakan bahwa "sebagai sekelompok pikiran dasar atau program mental yang dapat dimanfaatkan untuk meningkatkan efisiensi kerja dan kerjasama manusia yang dimiliki oleh suatu golongan masyarakat".

Moeheriono (2014:346) menyatakan budaya kerja adalah "cara pandang seseorang disertai dengan suasana hati yang didasari pada keyakinan yang diyakini terhadap kerja". Selain itu budaya kerja dapat diartikan secara praktis seperti pola nilai, sikap, tingkah laku, sistem kerja, teknologi dan bahasa yang digunakan. Berdasarkan beberapa pendapat diatas maka penulis menarik kesimpulan bahwa budaya kerja merupakan sikap dan perilaku seseorang ataupun sekelompok orang yang didasari atas nilai-nilai yang diyakini kebenarannya dan telah menjadi kebiasaan dalam menyelesaikan pekerjaan sehari-hari.

Berdasarkan beberapa pendapat diatas maka penulis menarik kesimpulan bahwa budaya kerja merupakan sikap dan perilaku seseorang ataupun sekelompok orang yang didasari atas nilai-nilai yang 
diyakini kebenarannya dan telah menjadi kebiasaan dalam menyelesaikan pekerjaan sehari-hari. Ada tiga indikator budaya kerja menurut Taliziduhu Ndraha (2005:212-214), antara lain: (1) Sikap terhadap kerja merupakan kecenderungan jiwa terhadap sesuatu dalam bekerja. Kecenderungan itu berkisar antara menerima sepenuhnya dengan menolak sekeras-kerasnya. Sikap terhadap pekerjaan dipengaruhi melalui: Informasi dan pengetahuan tentang kerja yaitu memperbesar volume ruang kognitif manusia dan dapat memperluas alternatif dan kesempatan kerja, sedangkan kesadaran akan kepentingan tertentu yaitu apabila kepentingan berubah maka sikap terhadap kerja juga berubah. Sikap juga bisa berubah dari positif (menerima), raguragu, negatif (menolak) terhadap kerja dan sebaliknya. (2) Perilaku di waktu bekerja merupakan sesuatu yang muncul setelah sikap yang semangat dalam bekerja maka akan berwujud perilaku seperti rajin, tidak cepat lelah, sungguh-sungguh, ramah, sabar, dan sebagainya. (3) Lingkungan kerja yaitu Lingkungan kerja dalam arti fisik dibangun berdasarkan prinsip-prinsip ergonomik. Ergonomics adalah studi tentang hubungan bioteknikal antara sifatsifat fisik manusia dengan tuntutan fisik pekerjaan. Hal ini pengkajian tentang hubungan manusia dengan alat kerja. Dalam bekerja manusia membangun lingkungan kerja yang nyaman dan menggunakan alat (teknologi) agar dapat bekerja efektif, efisien dan produktif. Dalam lingkungan kerja perilaku menentukan cara bagaimana seseorang menggunakan alat kerja.

Aldri Frinaldi, (2017b) mengungkapkan bahwa, "Driver work culture is a value believed and become a habit by a mass transporation driver in doing their work and will come up consciously while driving the vehicle, dealing with the passengers and other stakeholders in their work" (Budaya Kerja Pengemudi adalah adalah nilai yang diyakini dan menjadi kebiasaan oleh pengemudi transportasi massal dalam melakukan pekerjaan mereka dan mendatangkan kesadaran dan ketidaksadaran saat mengemudi kendaraan, berurusan dengan penumpang dan stakeholder lainnya dalam pekerjaan mereka).

\section{b. Transportasi}

Transportasi menurut Zulfiar Sani (2010:2) adalah perpindahan orang atau barang dari satu tempat ke tempat lainnya atau dari tempat asal ke tempat tujuan dengan menggunakan sebuah wahana yang digerakkan oleh manusia, hewan atau mesin. Transportasi menurut Miro dalam Ardiansyah, (2015:1) diartikan sebagai usaha memindahkan, menggerakkan, mengangkut atau mengalihkan suatu objek dari suatu tempat ke tempat lain, di mana di tempat lain ini objek tersebut lebih bermanfaat atau dapat berguna untuk tujuan-tujuan tertentu. Jadi, dapat disimpulkan bahwa transportasi merupakan suatu pemindahan barang atau orang dari suatu tempat ke tempat lain dengan menggunakan alat penggerak untuk mencapai tempat yang dituju.

Mulyono Sadyohutomo (2008:153-154) menjelaskan ada enam prinsip-prinsip dalam Penyelenggaraan layanan transportasi antara lain:

1) Aman yaitu pada prinsip ini mencakup rasa aman bebas dari cidera atau sampai merenggut jiwa. 
2) Nyaman yaitu manusia perlu mendapatkan rasa nyaman sejak persiapan, selama perjalanan, maupun sesudah menempuh perjalanan.

3) Mudah yaitu tingkat kemudahannya diukur dengan seberapa banyak pilihan yang tersedia bagi konsumen, seperti jenis kendaraan, rute perjalanan, jadwal waktu pelayanan, dan biaya. Semakin banyak pilihan tersedia menunjukkan tingkat kemudahan dan fleksiblitas perjalanan bagi masyarakat.

4) Ekonomis yaitu murah, terjangkau semua lapisan masyarakat.

5) Lancar yaitu pada perinsip ini menjamin ketepatan waktu dalam penyediaannya dan waktu tempuh yang sesingkat-singkatnya.

6) Ramah lingkungan yaitu tidak berdampak negatif (misalnya getaran, kebisingan, dan gas buang) yang dapat merusak lingkungan.

\section{c. Angkutan Kota}

Menurut Keputusan Menteri Perhubungan nomor 35 tahun 2003 pasal 1 butir 9 tentang penyelenggaraan angkutan orang di jalan dengan kendaraan umum mendefinisikan angkutan kota adalah angkutan dari satu tempat ke tempat lain dalam satu daerah kota atau wilayah ibukota kabupaten dengan menggunakan mobil bus umum atau mobil penumpang umum yang terikat dalam trayek. Berdasarkan Peraturan Pemerintah RI No. 74 Tahun 2014 pasal 1 butir 10 mendefinisikan mobil penumpang adalah kendaraan bermotor angkutan orang yang memiliki tempat duduk maksimal 8 (delapan) orang, termasuk untuk pengemudi atau yang beratnya tidak lebih dari 3.500 (tiga ribu lima ratus) kilogram.
Dalam Abbas Salim (2012:101) Ada empat fungsi angkutan jalan raya antara lain: (a) penyediaan angkutan kota, antar kota dan pendesaan berdasaran pada kebutuhan masyarakat, (b) untuk mengetahui layak jalan atau tidak dan alat angkut yang ada maka digunakan alat uji kendaraan bermotor, (c) angkutan jalan raya mengoperasikan pula jembatan timbang untuk menentukan kapasitas muat kendaraan, dan (d) fungsi lain yang dijalankan oleh transportasi darat ialah menyangkut rambu-rambu dan jalan, lampu lalu lintas serta meningkatkan keselamatan.

\section{d. Kepuasan}

Menurut Gibson, dkk dalam (Harbani Pasolong, 2010:144) menyatakan bahwa kepuasan pada hakikatnya berkaitan dengan faktor kebutuhan seseorang (pelanggan), jika kebutuhan seseorang terpenuhi maka orang tersebut merasa puas, demikian pula sebaliknya. Kepuasan menurut Oliver (dalam Supranto 2011:233) kepuasan adalah tingkat perasaan seseorang setelah membandingkan kinerja atau hasil yang dirasakannya dengan harapannya.

Di sisi lain, kepuasan pelanggan Ryzin mengatakan bahwa kepuasan (Dasman Lanin, 2017; Aldri Frinaldi, 2017c) "satisfaction is the consumenrs' or citizen summary' summary jugment about the product or service" (ringkasan konsumenrs atau ringkasan warga negara tentang produk atau layanan”. Vigoda dan Gadot (dalam Dasman Lanin, 2014) mengatakan bahwa "Satisfaction is related to the variable information that details of the views of citizen with a variety of public services at the national, local and 
community" (kepuasan berkaitan dengan variabel informasi yang detail pandangan warga dengan berbagai layanan publik di tingkat nasional, lokal dan masyarakat). Dan selanjutnya Muhammad Ali Embi (2015) mengatakan bahwa, "satisfaction or dissatisfaction of consumers or clients can be measured by their positive or negative response about the services they receive" (kepuasan atau ketidakpuasan konsumen atau klien dapat diukur dengan respon positif atau negatif mereka terhadap layanan yang mereka terima). Berdasarkan beberapa pendapat diatas maka penulis menarik kesimpulan bahwa kepuasan yaitu perasaan seseorang setelah membandingkan sesuatu yang diterima dengan yang diharapkan.

Dalam Permenpan Nomor 16 tahun 2014 tentang Pedoman Survei Kepuasan Masyarakat terhadap Penyelenggaraan Pelayanan Publik, untuk melakukan survei kepuasan pelanggan, pemerintah telah mengatur indikator-indikator yang digunakan untuk mengukur tingkat kepuasan masyarakat yaitu ada terdapat 9 (sembilan) ruang lingkup survei kepuasan masyarakat yang digunakan untuk mengukur tingkat kepuasan masyarakat, yaitu : (1) Persyaratan adalah syarat yang harus dipenuhi dalam pengurusan suatu jenis pelayanan, baik persyaratan teknis maupun administratif. (2) Prosedur adalah tata cara pelayanan yang dibakukan bagi pemberi dan penerima pelayanan, termasuk pengaduan. (3) Waktu adalah jangka waktu yang diperlukan untuk menyelesaikan seluruh proses pelayanan dari setiap jenis pelayanan. (4) Biaya/tarif adalah ongkos yang dikenakan kepada penerima layana dalam mengurus dan/atau memperoleh pelayanan dari penyelenggraan besarnya diteteapkan berdasarkan kesepakatan antara penyelenggara dan masyarakat. (5) Produk spesifikasi jenis adalah hasil pelayanan yang diberikan dan diterima sesuai dengan ketentuan yang telah ditetapkan. Produk pelayanan ini merupakan hasil dari setiap spesifikasi janis pelayanan.

Kompetensi pelaksana adalah kemampuan yang harus dimiliki oleh pelaksana meliputi pengetahuan, keahlian, dan pengalaman. (7) Perilaku pelaksana adalah sikap petugas dalam memberikan pelayanan. (8) Maklumat merupakan pernyataan kesanggupan kewajiban penyelenggara untuk melaksanakan pelayanan sesuai dengan standar pelayanan. (9) Penanganan pengaduan, saran dan masukan adalah tata cara pelaksanaan penanganan pengaduan dan tindak lanjut.

\section{Metode Penelitian}

Penelitian ini menggunakan metode kuantitatif deskriptif. Penelitian ini dilakukan disepanjang lintasan kode trayek 419 mulai dari M.Yamin - Bundo Kandung - Gereja - Diponegoro - Hang Tuah - Samudera - Simpang Sayonara Damar - Veteran - Juanda - S.Parman Hamka - Tabing - Adinegoro - Lubuk Buaya - Batas Kota. Populasi dalam penelitian ini adalah penumpang angkutan kota kode trayek 419 Pasar Raya-Lubuk Buaya Kota Padang sebanyak 1.184.400 orang. Sampel dalam penelitian ini diseleksi menggunakan rumus Slovin dengan tingkat kesalahan $5 \%$ dan menghasilkan sebanyak 400 sampel penumpang angkutan kota kode trayek 419 Pasar Raya-Lubuk Buaya Kota Padang. Pengambilan sampel dalam penelitian ini menggunakan teknik Simple Random 
Sampling. Pengumpulan data menggunakan angket yang dibagikan kepada penumpang angkutan kota kode trayek 419 Pasar Raya-Lubuk Buaya Kota Padang dan wawancara kepada penumpang dan pengemudi angkutan kota kode trayek 419 Pasar Raya-Lubuk Buaya Kota Padang sebagai data sekunder. Variabel dalam penelitian ini adalah (a) budaya kerja sebagai variabel independent (X); dan (b) variabel kepuasan penumpang sebagai variabel terikat (Y). Pengukuran data menggunakan skala likert. Data diperoleh kemudian dianalisis dengan menggunakan teknik regresi linear sederhana digunakan untuk menganalisis pengaruh budaya kerja pengemudi angkutan kota terhadap kepuasan penumpang angkutan kota kode trayek 419 Pasar Raya-Lubuk Buaya Kota padang. Dalam pengolahan data menggunakan SPSS versi 17

\section{Hasil dan Pembahasan}

\section{Karakteristik Responden}

Dalam penelitian ini responden berjumlah 400 orang penumpang angkot kode trayek 419 Pasar Raya-Lubuk Buaya Kota Padang, karakteristik responden dalam penelitian ini disajikan pada tabel berikut ini:

\section{Tabel 1. Karakteristik Responde}

\begin{tabular}{lcc}
\hline Karakteristik & $\begin{array}{c}\text { Frekuen } \\
\text { si }\end{array}$ & Persentase \\
\hline Jenis Kelamin & & \\
Laki-laki & 153 & $38.3 \%$ \\
Perempuan & 247 & $61.8 \%$ \\
\hline Umur & & \\
$\quad<20$ tahun & 126 & $31.5 \%$ \\
21-30 tahun & 137 & $34.5 \%$ \\
31-40 tahun & 50 & $12.5 \%$ \\
41-50 tahun & 29 & $7.3 \%$ \\
$>50$ tahun & 58 & $14.5 \%$ \\
\hline
\end{tabular}

\begin{tabular}{lcc}
\hline $\begin{array}{l}\text { Pendidikan } \\
\text { Terakhir }\end{array}$ & & \\
SD & 29 & $7.3 \%$ \\
SMP & 90 & $22.5 \%$ \\
SMA & 209 & $52.3 \%$ \\
D3/S1 & 69 & $17.3 \%$ \\
S2 & 3 & $0.8 \%$ \\
\hline Pekerjaan & & \\
$\quad$ Pelajar/Mahasi & 224 & $56.0 \%$ \\
swa & & \\
$\quad$ PNS & 27 & $6.8 \%$ \\
$\quad$ Karyawan & 61 & $15.3 \%$ \\
Swasta & & \\
$\quad$ Lain-lain & 88 & $22.0 \%$ \\
\hline Telah & & \\
Menggunakan & & \\
Angkot & & \\
$\quad$ 2-14 kali & 214 & $53.5 \%$ \\
$\quad$ > 14 kali & 186 & $46.5 \%$ \\
\hline
\end{tabular}

Dari tabel di atas dapat diketahui bahwa dari 400 responden, penumpang angkot kode trayek 419 Pasar Raya-Lubuk Buaya Kota Padang paling banyak adalah berjenis kelamin perempuan sebanyak 247 orang dengan persentase $61.8 \%$. Usia responden paling banyak berkisar dari 21-30 tahun sebanyak 137 orangdengan persentase $34.5 \%$, dan penumpang angkot paling banyak dengan berpendidikan terakhir adalah SMA sebanyak 209 orang dengan persentase $52,3 \%$ yang memiliki pekerjaan sebagai pelajar/ mahasiswa sebanyak 224 orang dengan persentase $56 \%$ dan responden yang telah menggunakan angkot berkisar 2-14 kali sebanyak 214 orang dengan persentase $53.5 \%$.

\section{Deskripsi Variabel Budaya Kerja Pengemudi Angkot}

Hasil Rata-rata skor variabel budaya kerja pengemudi angkot dan mean pada 
penelitian ini dapat dilihat pada tabel berikut:

\section{Tabel 2 Deskripsi Variabel Budaya Kerja}

\section{Item Pernyataan}

Mean

\begin{tabular}{ll}
\hline \multicolumn{3}{l}{ Sikap pengemudi angkot (X1.1) } & 3.31 \\
\hline $\begin{array}{l}\text { Perilaku pengemudi angkot } \\
(\mathrm{X} 1.2)\end{array}$ & 3.31 \\
\hline $\begin{array}{l}\text { Lingkungan Kerja pengemudi } \\
\text { angkot (X1.3) }\end{array}$ & 3.32 \\
$\begin{array}{l}\text { Rata-rata Variabel Budaya } \\
\text { Kerja pengemudi angkot }\end{array}$ & $\mathbf{3 . 3 2}$ \\
\hline
\end{tabular}

Berdasarkan tabel di atas dapat dilihat bahwa nilai mean variabel budaya kerja pengemudi angkot dapat dikategorikan cukup baik dan nilai meannya adalah 3,33 sebanyak 195 responden atau 49\% dari 400 responden. Jadi, dapat dikatakan bahwa sebagian responden menilai aspek budaya kerja dalam kategori cukup baik, karena nilai mean dan jawaban responden yang berada pada rentang 41\%-60\% termasuk ke dalam kategori cukup baik.

\section{Deskripsi Variabel Kepuasan Penumpang}

Rata-rata skor indikator kepuasan penumpang dan mean pada penelitian ini dapat dilihat pada tabel berikut:

\section{Table 3. Deskripsi Variabel kepuasan penumpang}

\section{Item Pernyataan}

Mean

Jelas informasi lintasan trayek yang dilayani tertempel pada bagian depan dan belakang angkot.
Sesuai perlakuan pengemudi

terhadap penumpang saat menaikkan dan menurunkan penumpang dengan standar yang berlaku.

\begin{tabular}{ll}
\hline $\begin{array}{l}\text { Pengemudi angkot ngetem } \\
\text { dengan waktu yang lama }\end{array}$ & 3.03 \\
\hline $\begin{array}{l}\text { Ongkos angkot sesuai dengan } \\
\text { ketentuan yang telah ditetapkan }\end{array}$ & 3.91 \\
oleh pemerintah daerah & \\
\hline $\begin{array}{l}\text { Pengemudi angkot menurunkan } \\
\text { penumpang sampai pada } \\
\text { tempat tujuan. }\end{array}$ & 3.31 \\
\hline $\begin{array}{l}\text { Pengemudi memiliki keahlian } \\
\text { dalam mengemudikan angkot. }\end{array}$ & 3.45 \\
\hline $\begin{array}{l}\text { Pengemudi mentaati peraturan } \\
\text { lalu lintas di jalan raya. }\end{array}$ & 3.07 \\
\hline $\begin{array}{l}\text { Pengemudi menyediakan } \\
\text { tempat sampah di dalam } \\
\text { angkot. }\end{array}$ & 2.95 \\
\hline $\begin{array}{l}\text { Pengemudi angkot cepat } \\
\text { merespon keluhan penumpang }\end{array}$ & 3.18 \\
\hline $\begin{array}{l}\text { Rata-rata indikator kepuasan } \\
\text { penumpang }\end{array}$ & $\mathbf{3 . 2 2}$ \\
\hline
\end{tabular}

Berdasarkan tabel 4.11 di atas dapat dilihat bahwa nilai mean variabel kepuasan penumpang dapat dikategorikan sedang dengan nilai mean adalah 3,22 sebanyak 177 responden dengan persentasi $44 \%$ dari 400 responden. Angka tersebut menunjukkan bahwa responden yang telah menggunakan angkot kode trayek 419 Pasar Raya-Lubuk Buaya Kota Padang menilai bahwa jelas informasi lintasan trayek tertempel pada bagian depan dan belakang angkot, sesuai perlakuan pengemudi terhadap penumpang saat menaikkan dan menurunkan penumpang dengan standar yang berlaku, pengemudi angkot ngetem denganwaktu yang lama, ongkos angkot sesuai dengan ketentuan yang telah ditetapkan oleh pemerintah 
daerah, pengemudi angkot menurunkan penumpang sampai pada tempat tujuan, pengemudi memiliki keahlian dalam mengemudikan angkot, pengemudi angkot mentaati peraturan lalu lintas di jalan raya,menyediakan tempat sampah di dalam angkot serta pengemudi angkot merespon keluhan penumpang. Jadi, dapat dikatakan bahwa rata-rata responden menilai bahwa aspekkepuasan penumpang angkot kode trayek 419 Pasar Raya-Lubuk Buaya Kota Padang berada dalam kategori cukup baik.

Table I. Pengaruh Budaya Kerja Pengemudi Angkot terhadap Kepuasan Penumpang

Model Summary ${ }^{b}$

Std.

Error of

$\mathrm{R}$ Adjuste the

Mo Squar d R Estimat Durbindel $R$ e Square e Watson

$\begin{array}{llllll}1 & .439^{\mathrm{a}} & .193 & .191 & 3.999 & 1.712\end{array}$

a. Predictors: (Constant), Budaya Kerja

Pengemudi Angkot

b. Dependent Variable: Kepuasan

Penumpang

Berdasarkan tabel di atas menghasilkan nilai Adjusted $R$ Square sebesar 0,191 atau sebesar $19,1 \%$ yang berarti kekuatan pengaruh budaya kerja mempengaruhi kepuasan penumpang., sedangkan sisanya $80,9 \%$ dipengaruhi oleh variabel lain yang tidak diteliti dalam penelitian ini. Hal tersebut berarti budaya kerja pengemudi angkutan kota mempengaruhi kepuasan penumpang angkot kode trayek 419 Pasar Raya-Lubuk Buaya Kota Padang sebesar $19,1 \%$.
Temuan ini memperkuat penelitian sebelumnya seperti penelitian yang dilakukan Gunadi, dkk (2016); Aldri Frinaldi (2017) bahwa budaya kerja pengemudi mempunyai signifikan kepuasan penumpang. Selanjutnya sejalan hasil penelitian Aldri (2017) dalam hasil penelitian angkutan kota di Kota Padang, sama hal dengan angkutan di Kota Painan Kabupaten Pesisir Selatan yaitu pada para pengemudi mempunyai budaya kerja yang melaju dengan kecepatan tinggi pada jamjam sibuk, karena alasan mengejar. Sedangkan di luar jam sibuk mereka sering berjalan pelan sekali dan ngetem dalam waktu lama, dengan alasan di luar jam sibuk jumlah penumpang tidak sebanyak pada jam-jam sibuk tersebut.

Selanjutnya untuk penelusuran lebih lanjut dari hasil analisis data kuantitatif diatas, maka peneliti melakukan wawancara dengan beberapa penumpang yang mana mereka mengungkapkan pengalaman mereka bahwa angkot kode trayek 419 Pasar Raya-Lubuk Buaya bahwa beberapa faktor penyebab kurang puas para penumpang disebabkan budaya kerja pengemudi terlihat dari sikap pengemudi angkot yang tidak bertanggung jawab dengan menurunkan penumpang tidak sampai tempat tujuan, lalu dipindahkan ke angkot lain atau diturunkan di tengah jalan begitu saja. Dan sikap pengemudi angkutan kota terkadang sopan dan terkadang tidak sopan dengan mengemudikan angkutan kota kebutkebutan, terjadi kecelakaan, keserempetan dengan kendaraan lain. pengemudi angkutan kota tidak sopan juga dibuktikan dengan pengemudi menurunkan penumpang masih keadaan mobil belum berhenti dengan baik, sehingga membuat 
penumpang terjatuh sebelum turun. Selain itu, pengemudi tetap menaikkan penumpang dengan keadaan tempat duduk penumpang dalam angkot sudah terisi penuh.Selanjutnya penumpang menilai perilaku pengemudi angkot masih kebutkebutan dengan mengemudikan kendaraan mobil dengan kecepatan tinggi, sehingga penumpang menjadi cemas dan duduk penumpang menjadi bergeser maka membuat penumpang mejadi tidak nyaman. Dan pengemudi angkutan kota (angkot) pada lingkungan kerjanya menyetelkan musik di dalam angkutan kota tergantung diwaktu tertentu saja seperti disaat sepi menyetelkan musik dengan volume keras dalam angkutan kota tetapi di saat ramai penumpang dalam angkutan kota tidak dinyalakan musik dengan volume yang keras.

Sesuai dengan ketentuan yang berlaku dibidang perhubungan (trasnportasi) kendaraan angkutan kota tidak dibenarkan menggunakan peralatan musik yang bervolume keras, termasuk mengubah standar keadaan kendaraan (tidak boleh kendaraan di “ceper"kan, knalpot dengan keras, kaca gelap). Meskipun pernah dilakukan razia oleh pihak yang berwenang terhadap kendaraan yang melanggar ketentuan tersebut, tetapi setelah razia berlalu, angkutan kota tersebut kembali "memoles" kendaraan seperti semula lagi.

Oleh sebab itu, menurut peneliti bahwa pihak berwenang harus senantiasa secara rutin melakukan razia kendaraan angkutan kota ini, misal seminggu sekali setiap bulannya, sehingga mereka (angkot) yang "memoles" kendaraan tidak berdasarkan standar ketentuan berlaku dapat menjadi jera.

\section{E. Kesimpulan}

Berdasarkan hasil analisis data dari pembahasan yang telah dijabarkan maka dapat disimpulkan bahwa budaya kerja pengemudi angkot kode trayek 419 Pasar raya-Lubuk Buaya Kota Padang dapat dikategorikan sedang, karena berada pada rentang nilai 41\%-61\% dengan nilai mean budaya kerja adalah 3,33 karena jawaban responden yang berada di atas mean 3,33 sebanyak 195 responden atau 49\% dari 400 responden. Angka tersebut menunjukkan bahwa penumpang menilai budaya kerja dalam kategori sedang. Sementara kepuasan penumpang angkot kode trayek 419 Pasar Raya-Lubuk Buaya Kota Padang pada budaya kerja pengemudi angkot berada dalam kategori sedang karena berada pada rentang $41 \%$ $60 \%$ yaitu sebanyak 177 responden $44 \%$ dari 400 responden menyatakan bahwa budaya kerja sedang.

Berdasarkan analisis data yang telah dilakukan maka dapat disimpulkan bahwa budaya kerja berpengaruh secara signifikan terhadap kepuasan penumpang. Variabel budaya kerja berpengaruh secara signifikan terhadap kepuasan penumpang karena signifikansi 0,000. Budaya kerja berkontribusi terhadap kepuasan sebesar $19,1 \%$ sedangkan sisanya $80,9 \%$ berkontribusi oleh variabel lain yang tidak diteliti dalam penelitian ini. Sehingga dapat dikatakan semakin besar kekuatan budaya kerja maka semakin besar juga kepuasan penumpang angkot kode trayek 419 Pasar Raya-Lubuk Buaya Kota Padang. Sementara kepuasan penumpang yang ada baru berkategori sedang 
sebanyak $44 \%$ saja.

\section{Daftar Pustaka}

Abbas Salim. 2012. Manajemen Transportasi. Jakarta: Rajawali Pers. Ardiansyah. 2015. Manajemen Transportasi dalam Kajian dan Teori. Jakarta Pusat: Penerbit Fakultas Ilmu Sosial dan Ilmu Politik Universitas Prof. Dr. Moestopo Beragama.

Aldri Frinaldi. (2017a). "The Influence of Work Culture on Work Performance of employees in Department of Transportation, Communcation and Informatics of West Sumatera" dalam Jurnal Ilmiah Wahana Bhakti Praja Vol.7 No.2. (pp:83-92).

Aldri Frinaldi. (2017b). "The Influence of Driver Work Culture and Service Quality on Citizen Satisfaction with Mass Transportation at South Pesisir Region West Sumatera, Indonesia" dalam Proceeding Advances in social science, Education and Humanities Research Vol.84. (pp:450-453).

Aldri Frinaldi, Muhamad Ali Embi, Yulvia Chrisdiana. (2017c). "The Effect of Work Culture and Service Quality on Train Service User's Satisfaction in West Sumatera" dalam Journal of Government and Politics Vol.10 No.2. (pp:415-435)

Aldri Frinaldi, Muhamad Ali Embi. (2015). "Influence of Public Service Quality in Citizen Satisfaction (Study in Private Hospital $\mathrm{Y}$ in Padang, West Sumatra Province)" dalam Journal of Government and Politics Vol.6 No.1. (pp:102-114).
Aldri Frinaldi, Muhamad Ali Embi. (2014). "Budaya Kerja Ewuh Pakewuh di Kalangan Pegawai Negeri Sipil Etnik Jawa (Studi Pada Kabupaten Pasaman Barat, Provinsi Sumatera Barat)" dalam Jurnal Humanus Vol.13 No.1. (pp:68-75).

Aldri Frinaldi. (2012). "Budaya Kerja Galie: (Studi Kasus Budaya Kerja Kalangan Pegawai Negeri Sipil Etnik Minangkabau di Kabupaten Pasaman Barat)" dalam Jurnal Humanus Vol.11 No.2. (pp:103111).

Aldri Frinaldi, Muhamad Ali Embi. (2011). "Pengaruh Budaya Kerja Etnik Terhadap Budaya Kerja Keadilan dan Keterbukaan PNS dalam Membangun Masyarakat Madani dan Demokrasi (Studi Pada Pemerintah Kabupaten Pasaman Barat)" dalam Jurnal Humanus Vol.10 No.1. (pp:52-61).

Asyrori. 2014. "Hubungan Budaya Kerja dengan Kinerja Pegawai di Kantor Kecamatan Sambutan Kota Samarinda. ejournal administrasi Negara" dalam Vol.5 No.3. (pp:1720-1733).

Dasman Lanin. (2014). "Citizen Satisfaction with Local Governance Service: The Influence of Manager Role on Public Service Inprovement in Local Government" dalam Jurnal Tingkap Vol.10 No.2. (pp:114-129).

Dasman Lanin, Nailuredha Hermanto. (2017). "The Reinforcement of Foreigner Satisfaction Concept in Immigration service in Indonesia" dalam Journal of Government and Politics Vol.8 No.2, (pp:201-227).

Gunadi, dkk. (2015). "Kualitas Pelayanan Sebagai Variabel Intervening antara 
Kompetensi Pegawai dan Budaya Kerja terhadap Kepuasan Mitra di Pelayanan Terpadu Satu Pintu Badan Pengusahaan Kawasan

Perdaganagan Bebas dan Pelabuhan Bebas Batam" dalam Jurnal Akuntasi, Ekonomi dan Manajemen Bisnis, Vol.3 No.1. (pp:56-65).

Harbani Pasolong. 2010. Teori Administrasi Publik. Bandung : Alfabeta

J. Supranto. 2011. Pengukuran Tingkat kepuasan pelanggan : Untuk Menaikkan Pangsa Pasar. Jakarta : Rineka Cipta.

Moeheriono. 2014. Pengukuran Kinerja Berbasis Kompetensi Edisi Revisi. Jakarta: Rajawali Pers.

Mulyono Sadyohutomo. 2008. Manajemen Kota dan Wilayah Realita dan Tantangan. Jakarta : Bumi Aksara

Peraturan Pemerintah Republik Indoensia Nomor 74 Tahun 2014 Tentang Angkutan Jalan

Keputusan Menteri Perhubungan Nomor:

KM. 35 Tahun 2003 Tentang Penyelenggaraan Angkutan Orang di Jalan dengan Kendaraan Umum

Peraturan Menteri Pendayagunaan Aparatur Negara dan Reformasi Birokrasi Nomor 16 Tahun 2014 tentang Pedoman Survei Kepuasan Masyarakat Terhadap Penyelenggaraan Pelayanan Publik.

Peraturan Daerah Kota Padang Nomor 11 Tahun 2005 Tentang Ketertiban Umum dan Ketentraman Masyarakat Padang Ekspres. "Tertibkan Angkot UgalUgalan”. 02 Januari 2017 pada pukul $7: 42$ http://www.koran.padek.co/read/deta $\mathrm{i} 1 / 21367$

Padang Ekspres. "Angkot Masih Ngetem diluar Pangkalan", 02 Februari 2017 pada pukul 07:40 WIB. http://www.news.padek.co.detail/a/2 3433

Taliziduhu Ndraha. 2005. Teori Budaya Organisasi. Jakarta : PT Rineka Cipta

Zulfiar Sani. 2010. Transportasi : Suatu Pengantar. Universitas Indonesia (UI-Press) : Jakarta 